\title{
Effect of salinity on the quantity and quality of carotenoids accumulated by Dunaliella salina (strain CONC-007) and Dunaliella bardawil (strain ATCC 30861) Chlorophyta
}

\author{
PATRICIA I GÓMEZ, ALEJANDRA BARRIGA, ANA SILVIA CIFUENTES \\ and MARIELA A GONZÁLEZ
}

Departamento de Botánica, Facultad de Ciencias Naturales y Oceanográficas, Universidad de Concepción. Chile

\begin{abstract}
Dunaliella salina and $D$. bardawil are well-known microalgae accumulating high levels of $\beta$-carotene under growth-limiting conditions. In both taxa, this pigment is primarily composed of the isomers 9-cis and all-trans. The 9-cis $\beta$-carotene occurs only in natural sources and is the most attractive from a commercial point of view. The conditions that enhance the preferred accumulation of 9-cis $\beta$-carotene in $D$. salina are controversial and they have not been well established yet. This study examined the effect of salinity on the quantity and quality of total carotenoids and $\beta$-carotene isomers accumulated by D. salina (strain CONC-007) and D. bardawil (strain ATCC 30861) grown in two media with different nutritional compositions (PES and ART) and at salt concentrations of $1 \mathrm{M}, 2 \mathrm{M}$ and $3 \mathrm{M} \mathrm{NaCl}$. Total carotenoids were determined by spectrophotometry and $\beta$ carotene isomers, by HPLC. The highest carotenoid contents per cell were obtained at $2 \mathrm{M} \mathrm{NaCl}$ in both taxa. In both media, an increase of the 9-cis/all-trans $\beta$-carotene ratio was observed in $D$. bardawil when the salt concentration increased, with a maximum value of 2.6 (in ART medium at $3 \mathrm{M} \mathrm{NaCl}$ ). In D. salina this ratio did not exhibit the same pattern, and the salt concentrations for maximal ratios were different in both media. The highest ratio obtained for this strain was 4.3 (in ART medium at $2 \mathrm{M} \mathrm{NaCl}$ ).
\end{abstract}

Key terms: D. salina, D. bardawil, ß-carotene isomers, salinity, culture medium.

\section{INTRODUCTION}

Dunaliella salina Teodoresco and Dunaliella bardawil Ben-Amotz \& Avron (nomen nudum of D. salina, according to Borowitzka and Borowitzka, 1988) have the exceptional ability of synthesizing and accumulating high amounts of $\beta$-carotene when maintained under growth limiting conditions (BenAmotz et al., 1982; Ben-Amotz et al., 1988; Borowitzka et al., 1984).

The $\beta$-carotene is a terpenoid pigment that is highly valuable due to its nutritional benefit as a precursor of vitamin $\mathrm{A}$ and for its antioxidant properties. In D. salina, the $\beta$ carotene is accumulated in electrodense globules located within the inter-thylakoid spaces in the chloroplast. The $\beta$-carotene occurs as a number of isomers, two of which, 9-cis and all-trans, make up approximately $80 \%$ of the total $\beta$-carotene in Dunaliella (Ben-Amotz et al., 1988; Borowitzka and Borowitzka 1988; Jiménez and Pick, 1994). The 9-cis isomer is synthesized only by natural sources and it is a highly valuable metabolite because of its interesting physicochemical properties i.e. it has a high liposolubility, being effectively preserved into animal tissues; furthermore, this isomer has proved to have a better antioxidant capacity than the all-trans isomer for which, at present, there have also been reports concerning its application in diseases related to the production of free radicals (Ben-Amotz et al., 1988; Jiménez and Pick, 1993; Becker, 1994). 
The extent of carotenoid accumulation in $D$. salina and D. bardawil has been extensively studied, and it is well established that it is triggered by high salinity (Borowitzka et al., 1990; Cifuentes et al., 1996a), high temperature and high irradiance (Ben-Amotz et al., 1988; Araneda et al., 1992) and also, under growth limiting nutritional conditions (Araneda et al., 1992; Markovits et al., 1993; Cifuentes et al., 1996b).

On the other hand, the conditions that favor the accumulation of 9-cis $\beta$-carotene have received much less attention and the information available is controversial. Regarding light, Ben-Amotz and co-workers (1988), working with D. bardawil ATCC 30861, detected an increase of the 9-cis/alltrans $\beta$-carotene ratio when increasing the photon flux density from 50 to $2000 \mu \mathrm{mol}$ $\mathrm{m}^{-2} \mathrm{~s}^{-1}$. On the contrary, Jiménez and Pick (1994), and more recently, Orset and Young (2000), found just the opposite, i.e., an increase of this ratio at decreasing photon flux densities (1500 to $50 \mu \mathrm{mol} \mathrm{m} \mathrm{m}^{-2} \mathrm{~s}^{-1}$ ) in two different strains of $D$. salina. Temperature is another parameter involved in the 9-cis $\beta$-carotene accumulation, since low temperature exposition $\left(10-15^{\circ} \mathrm{C}\right)$ has been reported to encourage specifically 9 -cis $\beta$-carotene production in D. bardawil (BenAmotz, 1996).

No reports have been published to date with respect to the effect of salinity on the 9-cis/all-trans $\beta$-carotene ratio. Considering that salinity is a parameter easy to control in outdoor cultures of Dunaliella for commercial purposes, the aim of this work was to study the effect of this parameter on the total carotenoids content and, specifically, on the 9-cis/all-trans $\beta$ carotene ratio in the Chilean strain $D$. salina CONC-007 and in D. bardawil strain ATCC 30861, cultured in two media with different nutritional composition.

\section{MATERIALS AND METHODS}

Algae: Two carotenogenic strains of Dunaliella were used for the experiments: $D$. salina CONC-007, isolated from the Atacama Desert, Chile $\left(23^{\circ} 30^{\prime} \mathrm{S} ; 68^{\circ} 15^{\prime} \mathrm{W}\right)$ and D. bardawil strain ATCC 30801, isolated from the Bardawil Lake, Egypt. Both strains are maintained in unialgal cultures in the Microalgae Culture Collection, University of Concepción, Chile.

Culture conditions: The strains were grown in two media i) Provasoli-enriched sea water medium (PES) (McLachlan, 1973), and ii) artificial medium (ART) (Ben-Amotz, 1988) (Table I) with different salinities: $1 \mathrm{M}, 2 \mathrm{M}$ and $3 \mathrm{M}$ of $\mathrm{NaCl}$. The experiments were carried out in $300-\mathrm{ml}$ Erlenmeyer flasks containing $150 \mathrm{ml}$ of the respective medium. The flasks were maintained under a continuous photon flux density of $40 \mu \mathrm{mol} \mathrm{m} \mathrm{m}^{-2} \mathrm{~s}^{-1}$ (provided from fluorescent day light tubes), at $25 \pm 1{ }^{\circ} \mathrm{C}$, without aeration and manually shaken twice a day. All the experiments were started by inoculating the flasks with exponentially growing cells acclimatized to the experimental conditions for 30 days. The initial cell density was approximately 5000 cells $\mathrm{ml}^{-1}$. Three replicates of each treatment were established.

Pigments analysis: The pigments were estimated in 28 day-old cultures (stationary phase). The total carotenoids and the chlorophyll were extracted from algal pellets using a $90 \%(\mathrm{v} / \mathrm{v})$ acetone/water mixture and determined by spectrophotometry (Wegmann and Metzner, 1971). For carotenoids per cell determination, counting was done in $1 \mathrm{ml}$ Utermöhl chambers.

Carotenoid composition was analyzed in dicloromethane extracts by HPLC using a chromatograph LDC Analytical with UVVisible detector. A stainless steel column of $25 \mathrm{~cm} \times 4 \mathrm{~mm}$ i.d. packed with C18 reversed phase material of $5 \mathrm{~mm}$ particle size was used. Elution was performed with

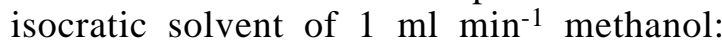
dicloromethane 90:10 v/v and a wavelength of $450 \mathrm{~nm}$ was utilized for detection. All solvents were filtered and degassed prior to use. Pigment identification was done by using synthetic $\beta$-carotene as standard (100\% all-trans isomer) and the elution order reported for these pigments in similar chromatographic systems (Ben-Amotz et al., 1988). The relative content of each carotene $(\alpha$-carotene, 9 -cis $\beta$-carotene and all-trans $\beta$-carotene) was determined 
TABLE I

Composition of media used in the cultures of two carotenogenic taxa of Dunaliella

\begin{tabular}{|c|c|c|}
\hline Chemical compound & Provasoli $(\mathrm{PES})^{(*)}$ & Artificial $(\mathrm{ART})^{(* *)}$ \\
\hline $\begin{array}{l}\mathrm{NaCl} \\
\mathrm{NaNO}_{3} \\
\mathrm{Na}_{2} \mathrm{glycerophosphate} 5 \mathrm{H}_{2} \mathrm{O} \\
\mathrm{FeCl}_{3} \times 6 \mathrm{H}_{2} \mathrm{O} \\
\mathrm{Na}_{2} \mathrm{EDTA}_{2} \times \mathrm{H}_{2} \mathrm{O} \\
\text { Vitamin B-12 } \\
\text { Thiamine } \\
\text { Biotin } \\
\text { Buffer TRIS } \\
\mathrm{H}_{3} \mathrm{BO}_{3} \\
\mathrm{CoSO}_{4} \times 7 \mathrm{H}_{2} \mathrm{O} \\
\mathrm{CuSO}_{4} \times 5 \mathrm{H}_{2} \mathrm{O} \\
\mathrm{CoCl}_{2} \times 6 \mathrm{H}_{2} \mathrm{O} \\
\mathrm{ZnCl}_{2} \\
\mathrm{ZnSO}_{4} \times 7 \mathrm{H}_{2} \mathrm{O} \\
\mathrm{MgSO}_{4} \\
\mathrm{MnCl}_{2} \times 4 \mathrm{H}_{2} \mathrm{O} \\
\left(\mathrm{NH}_{4}\right)_{6} \mathrm{Mo}_{7} \mathrm{O}_{24} \times 4 \mathrm{H}_{2} \mathrm{O} \\
\mathrm{CaCl}_{2} \\
\mathrm{KNO}_{3} \\
\mathrm{KH}_{2} \mathrm{PO}_{4} \\
\mathrm{NaHCO}_{3}\end{array}$ & $\begin{array}{c}1.0 \mathrm{M}-2.0 \mathrm{M}-3.0 \mathrm{M} \\
0.65 \mathrm{mM} \\
0.026 \mathrm{mM} \\
0.7 \mu \mathrm{M} \\
7.8 \mu \mathrm{M} \\
1.6 \mu \mathrm{g} \mathrm{l}^{-1} \\
8.0 \mu \mathrm{g}^{-1} \\
0.8 \mu \mathrm{g} \mathrm{l}^{-1} \\
0.66 \mu \mathrm{M} \\
72.0 \mu \mathrm{M} \\
0.07 \mu \mathrm{M} \\
\\
\\
0.3 \mu \mathrm{M} \\
\end{array}$ & $\begin{array}{c}5 \mathrm{mM} \\
0.2 \mu \mathrm{M} \\
0.3 \mu \mathrm{M} \\
0.3 \mathrm{mM} \\
0.75 \mu \mathrm{M} \\
0.2 \mu \mathrm{M} \\
50 \mu \mathrm{M} \\
\text { Complete volume with distilled water }\end{array}$ \\
\hline
\end{tabular}

(*) Natural enriched medium (**) Artificial medium.

estimating each peak's area respect to the integral of the areas.

\section{RESULTS}

Even though both strains exhibited their maximum growth rates at the lowest salinity $(1 \mathrm{M} \mathrm{NaCl}), D$. salina showed its maximum cell density at $2 \mathrm{M} \mathrm{NaCl}\left(1.1 \times 10^{6}\right.$ cells $\left.\mathrm{ml}^{-1}\right)$ while $D$. bardawil reached it at $1 \mathrm{M} \mathrm{NaCl}$ $\left(2.5 \times 10^{6}\right.$ cells $\left.\mathrm{ml}^{-1}\right)$ (data not shown).

Total carotenoids accumulated by the two strains of Dunaliella were affected by the medium composition. When production of total carotenoids per culture volume was compared in the two media at the same salinity, D. salina showed the highest values in ART medium, while D. bardawil showed it in PES medium (Table II). When the content of carotenoids per cell was compared, no clear tendency was observed: Dunaliella salina grown in PES medium showed the highest values at $1 \mathrm{M}$ and $2 \mathrm{M}$
$\mathrm{NaCl}$, whereas in ART medium the highest production was obtained at $3 \mathrm{M} \mathrm{NaCl}$. In $D$. bardawil, on the other hand, the highest values in this parameter were registered in PES medium at $1 \mathrm{M}$ and $3 \mathrm{M} \mathrm{NaCl}$, whereas in ART medium the greatest value was obtained at $2 \mathrm{M} \mathrm{NaCl}$ (Table II).

Only $D$. salina showed a clear tendency in accumulating more carotenoids per volume when increasing the salinity, being this response independent of the medium composition (Table II).

Carotenoids to chlorophyll ratio increased with salinity in $D$. salina, whereas $D$. bardawil showed the opposite tendency (Figure 1).

Under the culture conditions employed, $\alpha$-carotene was only detected in $D$. salina. The salinity did not affect the accumulation of $\alpha$ and $\beta$-carotene in this strain (Figure 2).

Dunaliella salina exhibited higher 9-cis/ all-trans $\beta$-carotene ratios than $D$. bardawil in both media and the three salinities used (Figure 3). 


\section{TABLE II}

Carotenogenesis parameters in D. salina and D. bardawil cultivated in two media (PES and ART) with different salinities (1M, 2M and $3 \mathrm{M} \mathrm{NaCl})$ after 28 days of incubation at $25^{\circ} \mathrm{C}$ and $40 \mu \mathrm{mol} \mathrm{m} \mathrm{m}^{-2}, \mathrm{n}=3 \pm \mathrm{SD}$.

\begin{tabular}{|c|c|c|c|c|c|c|}
\hline & \multicolumn{6}{|c|}{ D. salina } \\
\hline & \multicolumn{2}{|c|}{$1 \mathrm{M}$} & \multicolumn{2}{|c|}{$2 \mathrm{M}$} & \multicolumn{2}{|c|}{$3 \mathrm{M}$} \\
\hline & PES & ART & PES & ART & PES & ART \\
\hline Total carotenoids $\left(\mathrm{mg} \mathrm{l}^{-1}\right)$ & $6.9 \pm 1.3$ & $8.0 \pm 0.1$ & $10.8 \pm 0.6$ & $12.9 \pm 0.2$ & $12.9 \pm 0.5$ & $29.5 \pm 0.7$ \\
\hline \multirow[t]{4}{*}{ Total carotenoids (pg cell ${ }^{-1}$ ) } & $33.4 \pm 6.2$ & $14.0 \pm 0.1$ & $47.7 \pm 2.5$ & $14.2 \pm 0.1$ & $32.2 \pm 0.8$ & $36.3 \pm 0.8$ \\
\hline & \multicolumn{6}{|c|}{ D. bardawil } \\
\hline & \multicolumn{2}{|c|}{$1 \mathrm{M}$} & \multicolumn{2}{|c|}{$2 \mathrm{M}$} & \multicolumn{2}{|c|}{$3 \mathrm{M}$} \\
\hline & PES & ART & PES & ART & PES & ART \\
\hline Total carotenoids $\left(\mathrm{mg} \mathrm{l}^{-1}\right)$ & $23.3 \pm 0.7$ & $18.0 \pm 0.4$ & $24.7 \pm 0.6$ & $17.8 \pm 0.3$ & $23.0 \pm 0.9$ & $14.8 \pm 0.4$ \\
\hline Total carotenoids (pg cell ${ }^{-1}$ ) & $9.8 \pm 0.3$ & $7.2 \pm 0.2$ & $13.1 \pm 0.6$ & $26.9 \pm 0.4$ & $14.3 \pm 0.5$ & $7.5 \pm 0.2$ \\
\hline
\end{tabular}

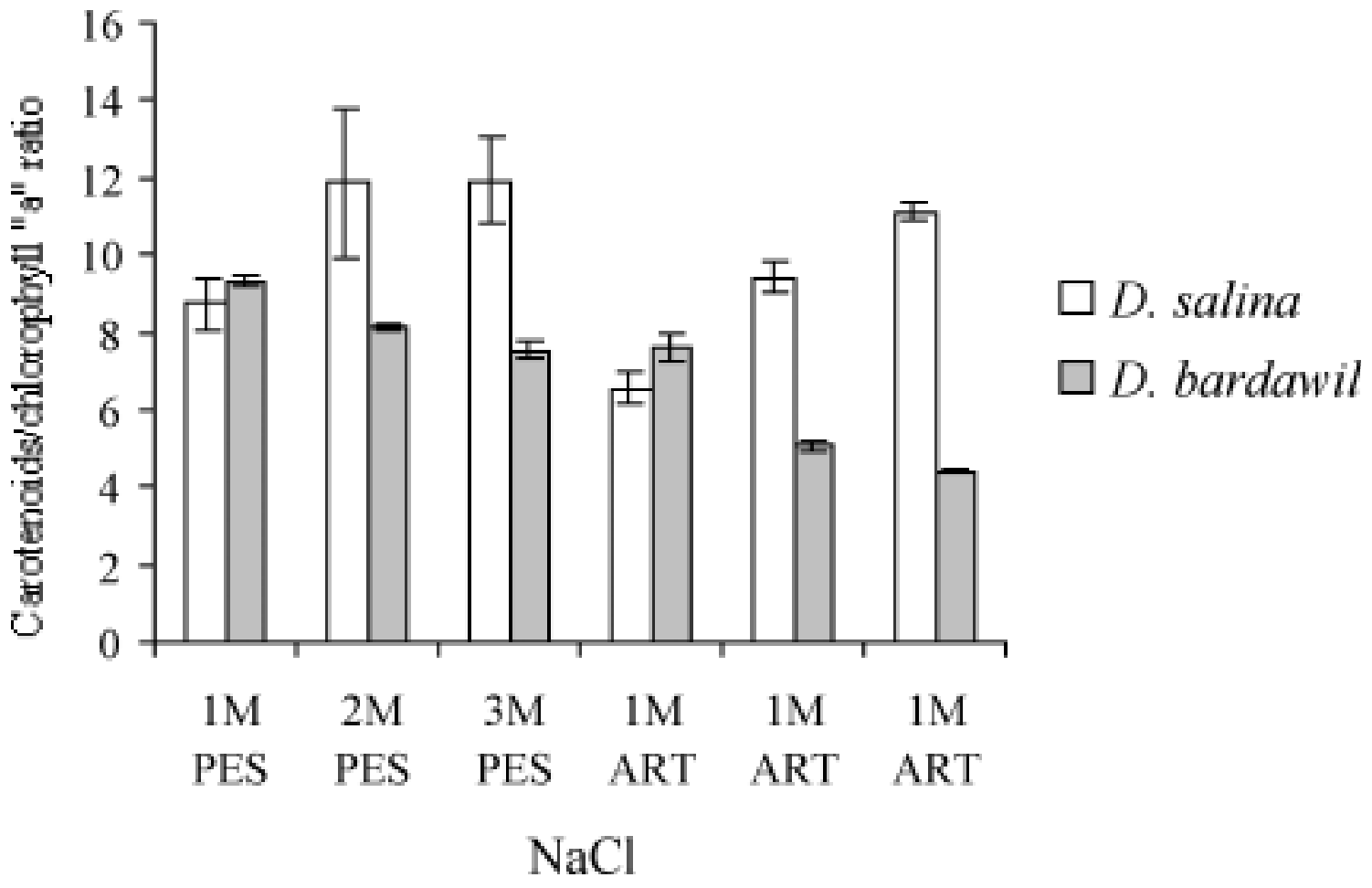

Figure 1

The effect of the medium composition and salinity on the carotenoid to chlorophyll "a" ratio in 28 day-old cultures of $D$. salina and $D$. bardawil, maintained at $25^{\circ} \mathrm{C}$ and $40 \mu \mathrm{mol} \mathrm{m}^{-2} \mathrm{~s}^{-1}(\mathrm{n}=3 \pm \mathrm{SD})$. 


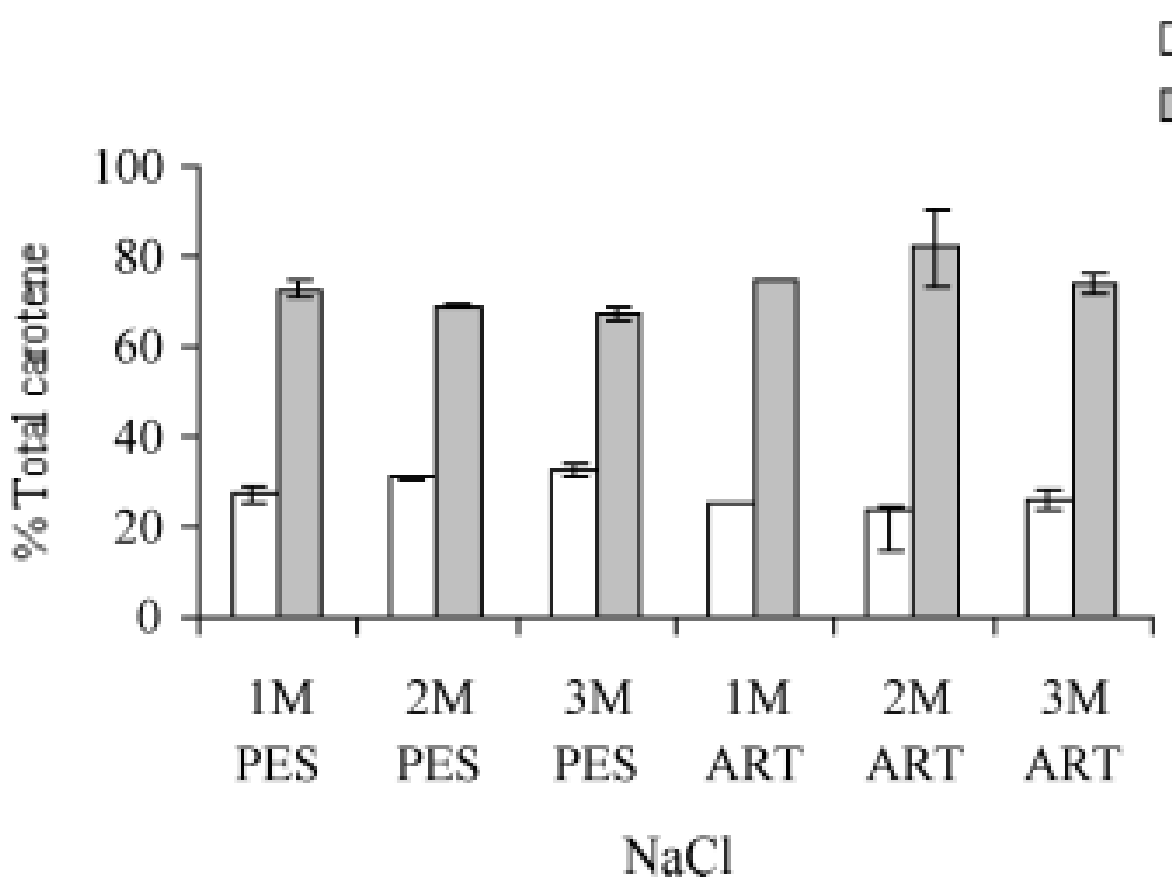

\section{Figure 2}

The effect of the medium composition and salinity on the $\alpha$ - and $\beta$-carotene percentage in 28 dayold cultures of D. salina strain CONC-007, maintained at $25^{\circ} \mathrm{C}$ and $40 \mu \mathrm{mol} \mathrm{m}^{-2} \mathrm{~s}^{-1}(\mathrm{n}=3 \pm \mathrm{SD})$.

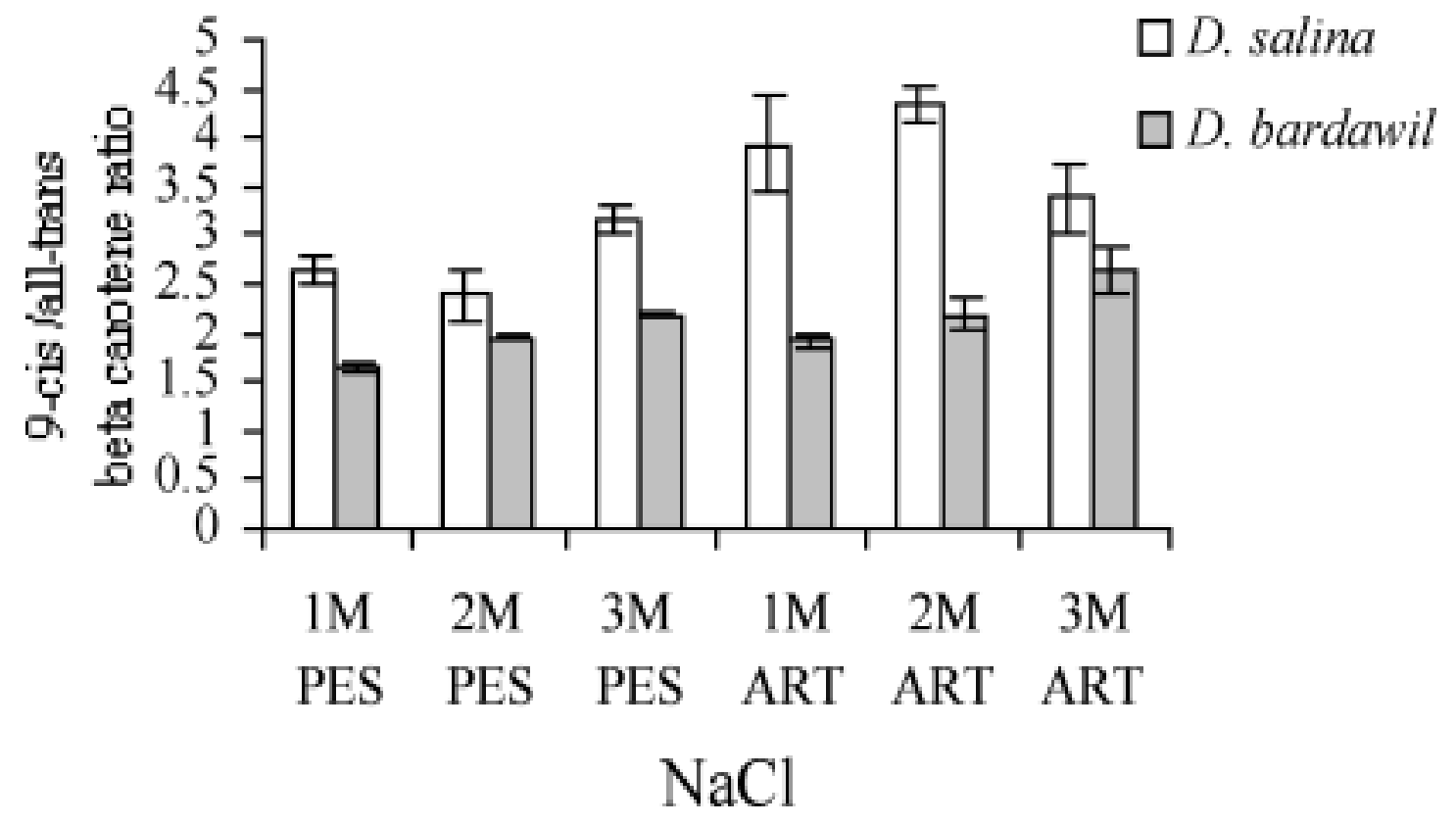

Figure 3

The effect of the medium composition and salinity on the isomeric composition of $\beta$-carotene in 28 day-old cultures of $D$. salina and D. bardawil, maintained at $25^{\circ} \mathrm{C}$ and $40 \mu \mathrm{mol} \mathrm{m}^{-2} \mathrm{~s}^{-1}(\mathrm{n}=3 \pm \mathrm{SD})$. 
In D. bardawil, the 9-cis/all-trans $\beta$ carotene ratio increased as the salinity of the medium increased. The maximum value was obtained in ART medium at $3 \mathrm{M} \mathrm{NaCl}$ (2.6). In D. salina, on the contrary, there was no a clear pattern (Fig. 3).

\section{DISCUSSION}

Both culture media used in this research have proven to be effective in inducing carotenogenesis in taxa of Dunaliella. The PES medium is an enriched natural medium, with a low supplement of nitrate and phosphate $\left(\mathrm{NaNO}_{3} \quad 0.65 \mathrm{mM}\right.$; $\mathrm{Na}_{2}$ glycerophosphate $\left.0.026 \mathrm{mM}\right)$. Cifuentes and co-workers (1996a, b) have demonstrated the effectiveness of this medium to induce carotenogenesis in several Chilean strains of $D$. salina. On the other hand, ART medium is an artificial medium already used by Ben-Amotz and co-workers (1988) in D. bardawil. Both media have similar nitrate concentrations (see Table I), but ART medium contains inorganic phosphate $\left(\mathrm{KH}_{2} \mathrm{PO}_{4}\right)$ at a concentration at least 10 times greater (0.026 versus 0.2) than the organic phosphate of PES medium (Table I).

It is interesting to note that despite the phosphate difference (source and concentration) in the two media, both strains of Dunaliella accumulated their maximum total carotenoids in either media (Table II). Since both media contain a limiting nitrogen contribution, this response can be explained by the well-known effect of limitation in this nutrient as an inductive factor of carotenogenesis in Dunaliella (Ben-Amotz et al., 1982)

Cifuentes and co-workers (1996a) analyzed the effect of the salinity on the accumulation of carotenoids per cell and on the carotenoids/ clorofila " $a$ " ratio in $D$. salina strain CONC-007 at stationary phase (3 months) when grew in PES medium. They found that a significant increase in these parameters is observed only above $15 \%$ $\mathrm{NaCl}$ (2.6 M). On the other hand, Orset and Young (1999) commented that the influence of salinity on carotenoid biosynthesis in $D$. salina does not show clear tendencies between 0.4 and $3.5 \mathrm{M} \mathrm{NaCl}$. In accordance to that, we did not observed a clear pattern on the accumulation of carotenoids per cell along the range $1 \mathrm{M}$ to $3 \mathrm{M} \mathrm{NaCl}$ in the two strains studied (Table II).

While in D. salina the carotenoids/ clorophyll " $a$ " ratio tended to increase with the salinity, in $D$. bardawil the opposite response was observed (Fig. 1). This result demonstrates the physiological differences exhibited by both strains cultivated in identical conditions, which have been previously observed even between strains of D. salina from very close geographic origins (Cifuentes et al., 1992; 1996b).

Neither the composition of the medium nor the salinity (in the tried range) significantly affected the accumulation of $\alpha$ and $\beta$-carotene of $D$. salina strain CONC007 (Fig. 2). That means that nitrogen limitation, per se, would induce the carotenogenesis in CONC-007 without affecting the relative amount of $\alpha$ and $\beta$ carotene. Similar to our results, Orset and Young (1999) did not find a clear effect of the salinity on the levels of $\alpha$-and $\beta$ carotene between $0.5 \mathrm{M}$ and $3.5 \mathrm{M} \mathrm{NaCl}$, obtaining a practically constant $\alpha$-carotene/ $\beta$-carotene ratio along this range.

The chemical composition of the culture medium, significantly affected the quality of $\beta$-carotene in both taxa. At the same salinity, the 9 -cis $\beta$-carotene isomer was preferentially accumulated in ART medium, a result that enhances the complexity of the carotenogenic response of Dunaliella, since the same variable significantly affects a parameter without affecting other closely related one (Figure 3). Unlike D. bardawil, D. salina, CONC-007 did not increase the 9cis/all-trans $\beta$-carotene ratio when the salinity increased (Fig. 3), this response can be explained by the intrinsic differences between the two strains, which could require different size stimuli for the preferential accumulation of 9-cis $\beta$-carotene.

Ben-Amotz and Avron (1983) and BenAmotz and co-workers (1988) reported that $\beta$-carotene accumulation, as well as 9-cis/ all-trans $\beta$-carotene ratio, increased in $D$. bardawil as a function of the amount of light that the alga received during a division cycle. If we consider that the photon flux 
density used in the present study was extremely low, the high values of the 9-cis/ all-trans $\beta$-carotene ratio obtained for both strains is surprising. Nevertheless, Jiménez and Pick (1994), and more recently Orset and Young (2000), found that the synthesis of 9 -cis $\beta$-carotene is promoted by low ( 50 $\left.\mu \mathrm{mol} \mathrm{m}^{-2} \mathrm{~s}^{-1}\right)$, rather than by high irradiances in some carotenogenic strains of Dunaliella. This finding could contribute to explaining the high proportion of 9 -cis $\beta$ carotene accumulated by both taxa at 40 $\mu \mathrm{mol} \mathrm{m} \mathrm{m}^{-2} \mathrm{~s}^{-1}$ (Fig. 3).

Orset and Young (2000) also found that in cultures at its logarithmic phase of growth, the 9-cis/all-trans $\beta$-carotene ratio increased from 0.2 to more than 2.1 at the stationary phase, demonstrating the importance of the harvesting time for obtaining high proportions of the 9-cis isomer. Even more, these results allow us to find an explanation for the high values of the 9-cis/all-trans $\beta$-carotene ratio obtained here for D. bardawil (2.2, Figure 3) under the same culture conditions used previously by Ben-Amotz and co-workers (Ben-Amotz et al., 1988, pp:1287). The latter group of authors do not clearly explain the period of growth at which the cultures were analyzed but, according to the data obtained from our study, it can be assumed that they were in the exponential phase of growth.

Considering the increasing biotechnological interest in searching for highly carotenogenic taxa of Dunaliella, showing high 9-cis/all-trans $\beta$-carotene ratios, the high values of this ratio obtained for the Chilean strain CONC-007 in ART medium at $1 \mathrm{M}$ and $2 \mathrm{M} \mathrm{NaCl}$ (3.9 and 4.3 respectively, see Fig. 3) give new argument to considering it as a very promising strain for biotechnological applications.

The carotenogenic strains of Dunaliella studied showed great physiological plasticity in response to both culture media and salinity. The combination of both factors proved to have a complex effect on the amount and quality of the carotenes accumulated. The results demonstrated that there is no set of unique conditions that favor the carotenogenesis in these microalgae, and that there is a great relevance in the intrinsic capacity of each strain to respond to inductive factors of this ability. In this sense, recent investigations have demonstrated an interesting correlation between the carotenogenic capacity of D. salina strains and polymorphisms at level of their genome (Gómez and González, 2001).

\section{ACKNOWLEDGEMENTS}

This work was supported by FONDECYT Grant Nº 2990047 to Patricia Gómez.

\section{REFERENCES}

ARANEDA P, JIMÉNEZ C, GÓMEZ-SILVA B (1992) Microalgae from Northerm Chile III. Growth and betacarotene content of three isolates of Dunaliella salina from the Atacame Desert. Revista de Biología Marina de Valparaíso (Chile) 27: 157-162

BECKER EW (1994) Chemical composition. Applications of algae. In BECKER EW (ed) Microalgae: Biotechnology and Microbiology. Cambridge University Press, London. pp. 177-195, 250-260

BEN-AMOTZ A (1996) Effect of low temperature on the stereoisomer composition of $\beta$-carotene in the halotolerant alga Dunaliella bardawil (Chlorophyta). J Phycol. 32: 272-275

BEN-AMOTZ A, AVRON M (1983) On the factors which determine massive $\beta$-carotene accumulation in the halotolerant alga Dunaliella bardawil. Plant Physiol 72: 593-597

BEN-AMOTZ A, KATZ A, AVRON M (1982) Accumulation of $\beta$-carotene in halotolerant algae: purification and characterization of $\beta$-carotene-rich globules from Dunaliella bardawil (Chlorophyceae). J Phycol 18:529-537

BEN-AMOTZ A, LERS A, AVRON M (1988) Stereoisomers of $\beta$-carotene and phytoene in the alga Dunaliella bardawil. Plant Physiol 86: 1286-1291

BOROWITZKA M, BOROWITZKA L (1988). Dunaliella. In: BOROWITZKA M, BOROWITZKA L (eds) Microalgal Biotechnology Cambridge University Press, Cambridge. pp: 27-58

BOROWITZKA M, BOROWITZKA L, KESSLY D (1990) Effects of salinity increase on carotenoid accumulation in the green alga Dunaliella salina. J Appl Phycol 2: 111-119

BOROWITZKA M, BOROWITZKA L, MOULTON T (1984) The mass culture of Dunaliella salina for fine chemicals: From laboratory to pilot plant. Hydrobiol 116/117: 115-121

CIFUENTES A, GONZÁLEZ M, CONEJEROS M, DELLAROSSA V, PARRA O (1992) Growth and carotenogenesis in eight strains of Dunaliella salina Teodoresco from Chile. J Appl Phycol 4: 111-118

CIFUENTES A, GONZÁLEZ M, PARRA O (1996a). The effect of salinity on the growth and carotenogenesis in two Chilean strains of Dunaliella salina Teodoresco. Biol Res 29: 227-236

CIFUENTES A, GONZÁLEZ M, PARRA O, ZÚÑIGA M (1996b) Cultivo de cepas de Dunaliella salina (Teodoresco 1905) en diferentes medios bajo 
condiciones de laboratorio. Rev Chilena Hist Nat 69: $105-112$

GÓMEZ P, GÓNZALEZ M (2001) Genetic polymorphism in eight Chilean strains of the carotenogenic microalga Dunaliella salina Teodoresco (Chlorophyta). Biol Res 34: 23-30

JIMÉNEZ C, PICK U (1993) Differential reactivity of bcaroteno isomers from Dunaliella bardawil toward oxygen radicals. Plant Physiol 101: 385-390

JIMÉNEZ C, PICK U (1994) Differential stereoisomer compositions of $\mathrm{b}, \beta$-carotene in thylakoids and in pigment globules in Dunaliella. J Plant Physiol 143: 257-263

MARKOVITS A, GIANELLI M, CONEJEROS R, ERAZO S (1993) Strain selection for $\beta$-carotene production by Dunaliella. World J of Microbiol and Biotech 9: 534-537

MCLACHLAN J (1973) Growth-media-marine. In: STEIN JR (ed) Handbook of Phycological Methods. Culture Methods and Growth Measurements London: Cambridge University Press. Pp: 25-51

ORSET S, YOUNG A (1999) Low temperature induced synthesis of $\alpha$-carotene in the microalga Dunaliella salina (Chlorophyta). J Phycol 35: 520-527

ORSET S, YOUNG A (2000) Exposure to low irradiances favors the synthesis of 9-cis $\beta, \beta$-carotene in Dunaliella salina (Teod). Plant Physiol 122: 609-617

WEGMANN K, METZNER H (1971) Synchronization of Dunaliella salina cultures. Archiv für Mikrobiologie 78: $360-367$ 